\title{
UNDERSTANDING ELECTRICAL TREEING PHENOMENA IN XLPE CABLE INSULATION ADOPTING UHF TECHNIQUE
}

\author{
Ramanujam Sarathi * Arya Nandini * Michael G. Danikas **
}

\begin{abstract}
A major cause for failure of underground cables is due to formation of electrical trees in the cable insulation. A variety of tree structure can form from a defect site in cable insulation viz bush-type trees, tree-like trees, fibrillar type trees, intrinsic type, depending on the applied voltage. Weibull studies indicate that a higher applied voltage enhances the rate of tree propagation thereby reducing the life of cable insulation. Measurements of injected current during tree propagation indicates that the rise time and fall time of the signal is of few nano seconds. In the present study, an attempt has been made to identify the partial discharges caused due to inception and propagation of electrical trees adopting UHF technique. It is realized that UHF signal generated during tree growth have signal bandwidth in the range of $0.5-2.0 \mathrm{GHz}$. The formation of streamer type discharge and Townsend type discharges during tree inception and propagation alters the shape of the tree formed. The UHF signal generated due to partial discharges formed during tree growth were analyzed adopting Ternary plot, which can allow one to classify the shape of tree structure formed.
\end{abstract}

K e y w o r d s: power cables, cable insulation, partial discharge, UHF signal, electrical breakdown, failure analysis, XLPE, ternary plot

\section{INTRODUCTION}

In recent times, cross linked polyethylene (XLPE) material is used as insulation material in high voltage $\mathrm{AC}$ and DC cables. With the advancement in polymer technology, it has become essential to identify a material for cable insulation with high dielectric strength, low permittivity, low loss tangent and with good mechanical strength. However, there is also considerable evidence that defects in the insulation structure can cause premature failure of insulation structure. The failure of underground cable in service can cause long interruption in supply of power to the customers. Early detection of failure can prevent such failures and by adopting preventive measures, it would be possible to improve the power system reliability and its operation. The life expectancy of the underground cables is adversely affected by Electrical Treeing, a pre-breakdown phenomenon and accounts for its pre-mature failure [1]. In underground cables, under normal operating voltage, the partial discharges incepts pre-breakdown channels from a region of defect site present in the form of gas cavities or conducting inclusions or intrusions, in the insulation structure, due to field enhancement. These pre-breakdown channels emanated from the defect site in the insulation structure resemble branches of a tree and, hence, the name "treeing" is given to the damage process and since such an occurrence is purely due to electrical stress the mechanism is termed as "Electrical Treeing" [2-5]. In general, the partial discharge injected current pulses involve rise and fall-times of about $1 \mathrm{~ns}$ or less, exciting signals in the UHF range of $300-3000 \mathrm{MHz}$ [6].
The conventional method of identifying the discharges is through identification of luminous discharges from the defect site due to tree propagation, acoustic signal radiated during tree propagation and by measuring the partial discharge magnitude [7-10]. Ueno et al, studied treeing phenomena in epoxy resin insulating material and they could identify the point of inception and propagation adopting UHF technique [11]. However, adoption of UHF technique for identification of incipient discharges in underground cable insulation diagnostics is at an infancy stage.

Hence in the present work, a methodical experimental study was carried out to understand the feasibility of using broad band sensors, to identify any UHF signal radiated during partial discharges causing tree growth and for classification of shape of tree structure that has formed. Generation of electrical trees in actual cables is a cumbersome process. It is not possible to visualize the tree growth. The cable insulation has to be microtomed and have to visualized with sophisticated equipments. Hence it is essential to identify the point of inception using nonintrusive type sensor and to provide information regarding the shape of tree structure formed. The sensor signal generated due to incipient discharges during tree growth was used for constructing the ternary diagram for classifying the different shapes of tree structure that forms.

\section{EXPERIMENTAL STUDIES}

The experimental setup used for generating the electrical trees and measurement of UHF signal generated due

\footnotetext{
* Department of Electrical Engineering, IIT Madras, Chennai-600 036, India; rsarathi@iitm.ac.in ${ }^{* *}$ Department of Electrical and Computer Engineering Democritus University of Thrace, Xanthi, Greece.
} 


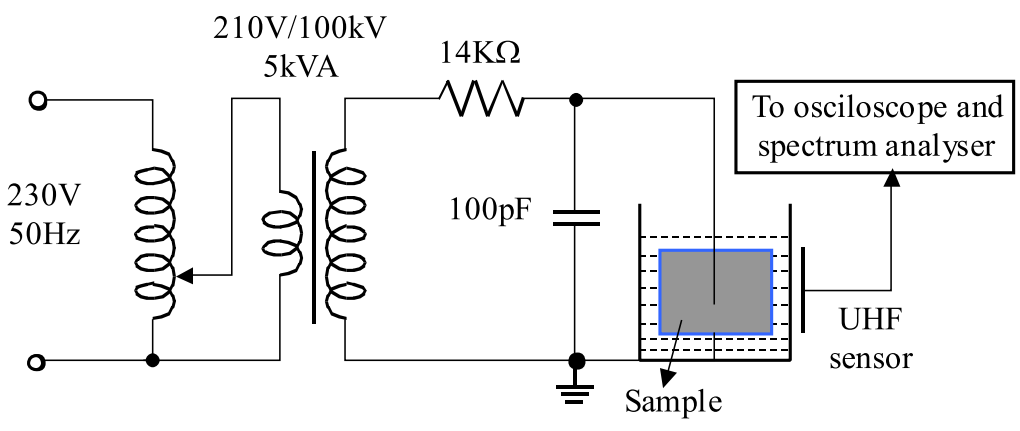

Fig. 1. Experimental Setup



Fig. 2. Frequency response of the UHF sensor

to partial discharges in the cable insulation system during the electrical tree formation, under the AC voltage is shown in Fig. 1. The experimental setup could be sectionalized in to three parts. The first, second and third part of the experimental setup covers the high AC voltage source, sample preparation and methodology of testing and the UHF sensor respectively. The details of each section are as follows.

\subsection{High voltage source}

The high AC voltages were generated by using $100 \mathrm{kV}$, $5 \mathrm{kVA}$ discharge free test transformer. The applied AC voltage was measured using a capacitance divider. The $\mathrm{AC}$ voltage was increased at a rate of $300 \mathrm{~V} / \mathrm{s}$ up to the required test voltage level.

\subsection{Sample preparation and methodology of testing}

In the present work, electrical trees were generated in a $33 \mathrm{kV}$ XLPE cable insulation. The cable insulation is cut in to regular size of $1 \mathrm{~cm}$ thick. A conducting defect was simulated by inserting a sharp metallic needle into the insulation, which is connected to the high voltage terminal. The centre conductor of the cable is connected to the ground. Since the needle tip is sharp and near to the ground terminal, the local field enhancement occurs near to the pin tip causing localized discharges/damage near the needle tip. The needle used had a nominal tip radius of curvature, $5 \mu \mathrm{m}$. The effective thickness between the tip of the needle electrode and ground electrode was maintained between $3-5 \mathrm{~mm}$. The space between the pin and the dielectric was effectively sealed with the cold setting araldite and the specimens were immersed in filtered, degassed mineral transformer oil ready for voltage application.

\subsection{UHF sensor}

The UHF sensor is a non-intrusive type sensor which can provide the information about source of partial discharge occurrences. One of the fundamental requirements of the UHF sensor for identification of partial discharges is that, it must have a broadband response. Also the sensor should have minimum sensitivity in the range 500 to $1500 \mathrm{MHz}$ [12]. Martin et al, have carried out a detailed study on partial discharges in transformers using the sensors (that are) used in gas insulated systems and realized that the same sensor could be utilized for monitoring incipient discharges in transformers $[13,14]$. The sensitivity response of the broad band sensor is shown in Fig. 2.

In the present study, UHF sensor used for detection of partial detection activity it is adopted to identify the tree growth process by placing the sensor at a distance of $20 \mathrm{~cm}$ away from the sample holder. The output of the UHF sensor is connected to the spectrum analyzer/high bandwidth digital storage oscilloscope. The UHF signals were captured using a digital storage oscilloscope (LeCroy, 4 channel, $3 \mathrm{GHz}$ bandwidth, operated at $10 \mathrm{GSa} / \mathrm{s}$ ) with an input impedance of $50 \mathrm{ohms}$. The spectrum analyzer Hewlett Packard E4402B ESA-ESeries was used to measure the signal in zero span mode with $1 \mathrm{GHz}$ centre frequency.

\section{RESULTS AND DISCUSSION}

\subsection{Influence of Electrical Stress on the Size and Shape of Tree Growth}

The major cause of failure of underground cable insulation is due to formation of electrical trees from a defect site in it. The defect in the insulation structure can be 

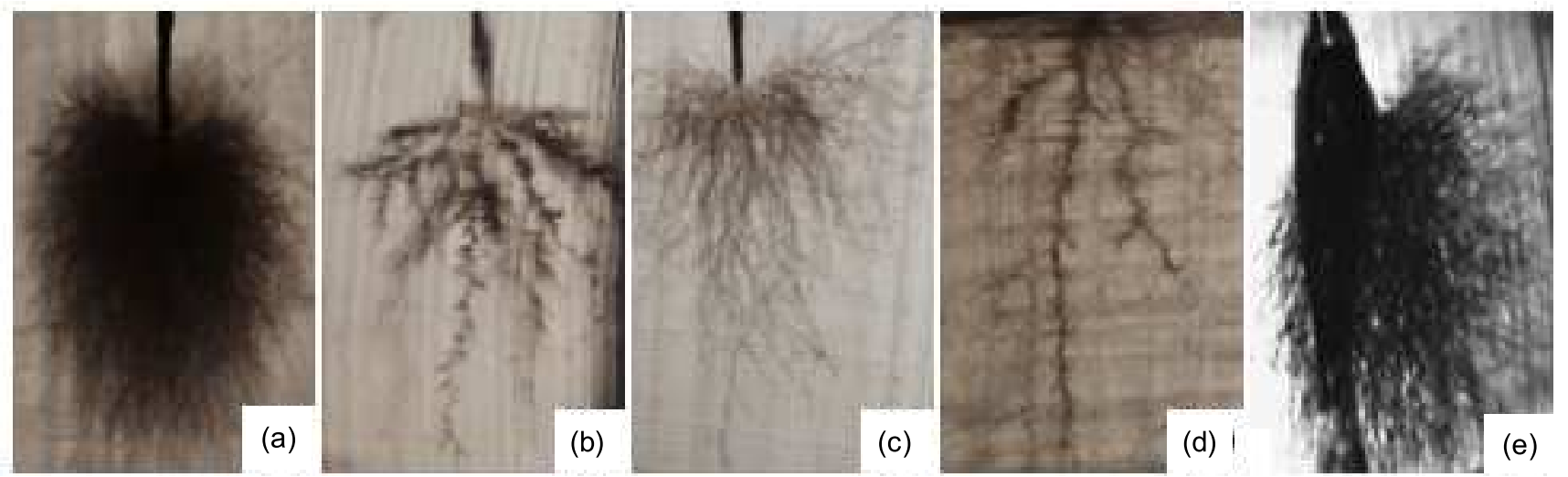

Fig. 3. Electrical Tree in XLPE cable Insulation under AC voltage (a) Bush Type Tree (b) Tree-Like-Tree (c) Fibrillar type tree (d) Intrinsic type tree (e) Tree Followed with Breakdown insulation

a conducting/non-conducting defect. The size and shape of the defect vary the local electric field, which alter the shape of tree and its mode of propagation. To generate electrical trees in an insulation structure, selecting the applied voltage magnitude is very important. If the stress is of larger magnitude intrinsic type, failure can occur with few pre-breakdown channels and if it is less, no tree can form in the insulation structure.

Mason [15] suggested that electric field $\left(E_{\max }\right)$ at the tip of the needle electrode can calculated as

$$
E_{\max }=\frac{2 U d}{r \ln \left(1+\frac{4 d}{r}\right)}
$$

where $r$ is the weighted mean average of tip radius of curvature of the needle electrode, $d$ is the thickness of the insulation from the needle tip to the center conductor of the cable insulation and $U$ is the applied voltage magnitude. By carefully selecting the operating voltage for the tree inception, different tree patterns were generated and analyzed. Figure 3 shows the optical photographs of different type of electrical trees formed in the XLPE cable specimen under the $\mathrm{AC}$ voltages. It is observed that bush type of Tree (Fig. 3a), a tree like tree (Fig. 3b) a fibrillar type Tree (Fig. 3c) and an intrinsic type tree structures (Fig. 3d) are formed at the tip of the needle electrode, which is connected to high voltages. Figure 3e shows a typical breakdown path formed in the insulation structure due to propagation of electrical tree and terminating to the ground electrode.

When a high voltage is connected to the needle electrode, the local electrical field near the needle tip enhances and if the local electric field exceeds the breakdown strength of the material, partial discharge incepts and causes a localized incipient damage to the insulation structure forming a tree like tree. Depending on the magnitude of applied voltage, conductivity of the medium in the defect zone and the local electric field condition at the point of inception of electrical tree, a fibrillar type, intrinsic type failure, tree like tree or a bush type of electrical tree can form. When a localized incipient damage occurs, injection of charges from the high voltage electrode to the insulation structure were trapped near the defect site formed and the charges gets deposited in the surface of the damaged zone causing local reaction with the applied field reducing the electric field in the zone. Sometimes, the homo or hetero charges were also injected into the insulation structure through the defect formed zone-enhancing field at one point causing further enlargement of channel resulting in Tree-Like- Tree structure. Otherwise local discharges will occur causing increased diameter of the damage zone forming bush Type of electrical tree. Sometimes, the local electric field near edge of the defect zone be high allowing fibrillar Type or intrinsic type electrical tree to form. Ansheng et al, suggested that when the needle is inserted into large spherulites, conducting trees will form in those spherulites. When the needle is inserted among spherulites, non-conducting trees will appear along the boundaries of spherulites indicating that different types of electrical trees occurs [16]. Yoshimura et al, carried out optical studies and have concluded that on application of voltage a tree like tree pattern appears and if the voltage is further increased discharges at the tree tip be high forming fibrillar or bush type tree structure [17].

In the present work, 20 identical samples were used to obtain failure times of the specimen due to electrical trees. The study was carried out at different voltage levels. The voltage was applied to the specimen simultaneously and the time instant the failure occurred was noted. In the present study, censored data analysis was used to estimate the characteristic time of failure of insulating material due to treeing. Only 10 failure times were noted and the remaining samples were cut and examined visually for any tree structure formation. Even though the samples are identical, the scatter in the failure times of the specimens is large. It is essential to utilise statistical tools to understand the severity due to electrical stress. The two parameter cumulative Weibull distribution function is given by [18]

$$
F(t)=1-\exp \left(-\frac{t}{\tau}\right)^{\beta}
$$




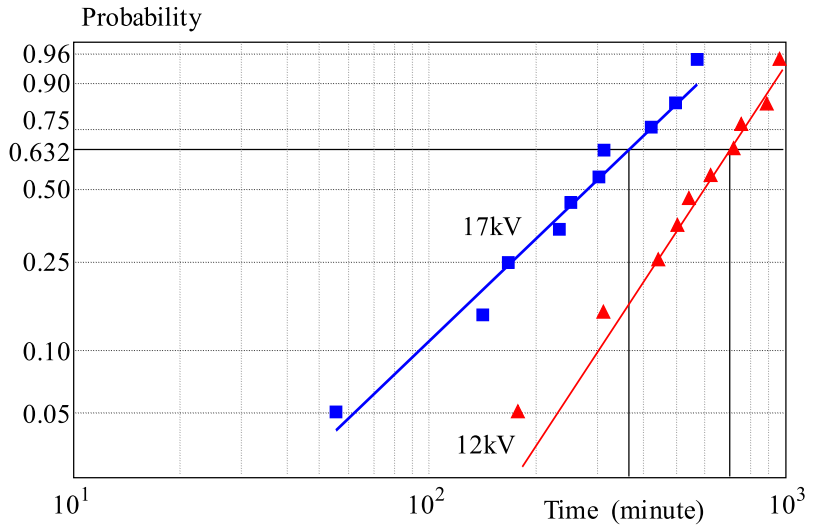

Fig. 4. Weibull plot for the failure times of the insulation structure due to electrical trees

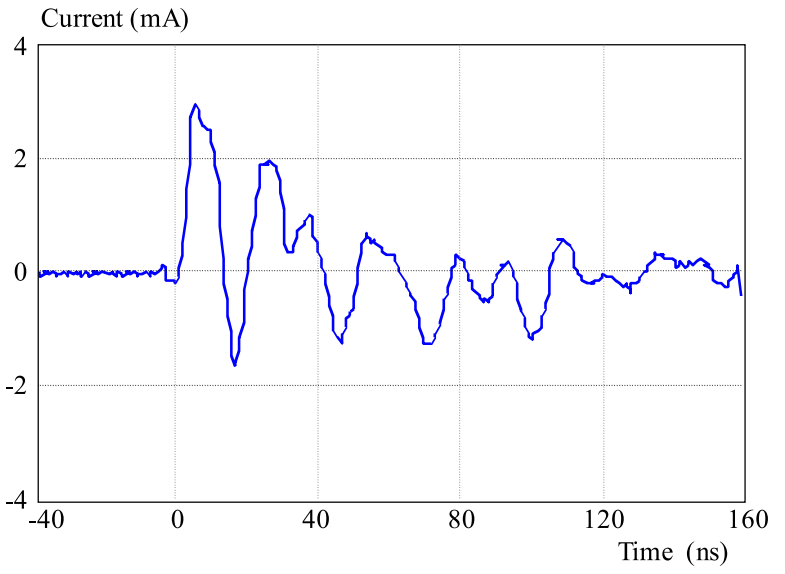

Fig. 5. Typical Injected current pulse formed due to partial discharges

where $\tau$ is the scale parameter, $\beta$ is the shape parameter and $t$ is the random variable, usually time to breakdown. $F(t)$ indicates the proportion of specimens tested which will fail by time $t$. The scale parameter represents the time required for $63.2 \%$ of tested units that fail. The shape parameter is a measure of dispersion of failure times [18].

Table 1. Variation in Characteristic life and shape parameter for the failure data caused due to electrical treeing

\begin{tabular}{ccc}
\hline Applied & Characteristic & Shape \\
Voltage & Life in mins & Parameter \\
\hline $12 \mathrm{kV}$ & 677 & 2.68 \\
$17 \mathrm{kV}$ & 331 & 2.03 \\
\hline
\end{tabular}

Figure 4 shows the Weibull plot for the failure times of the insulation structure due to electrical trees, operated at different voltage levels. Table 1 shows the variation in the characteristic life of the insulation material and the shape parameter for the failure data caused due to electrical treeing, at different voltage levels. It is observed very clearly that increase in magnitude of applied voltage shows a reduction in the characteristics life of the insulation material. In addition, it is noticed that the slope parameter $(\beta)$ obtained under different electrical stress is varying. It is clear that if the $\beta$ value is more than one, which is an indication that the failure of the insulation material is due to local erosion causing failure of insulation structure. Raetzke et al, carried out work on epoxy nanocomposites and they have observed that failure of epoxy resin due to electrical tree can drastically be reduced by incorporating nano filler to the insulating material [19]. Xie et al, carried out electrical treeing studies in $110 \mathrm{kV}$ XLPE cable insulation and have concluded that insulating material having narrow molecular weight distribution with lower impurity, the material will have higher treeing resistance [20]. Thus by mitigating the impurity level in the cable insulation, it is possible to reduce the cable insulation failure due to electrical treeing.
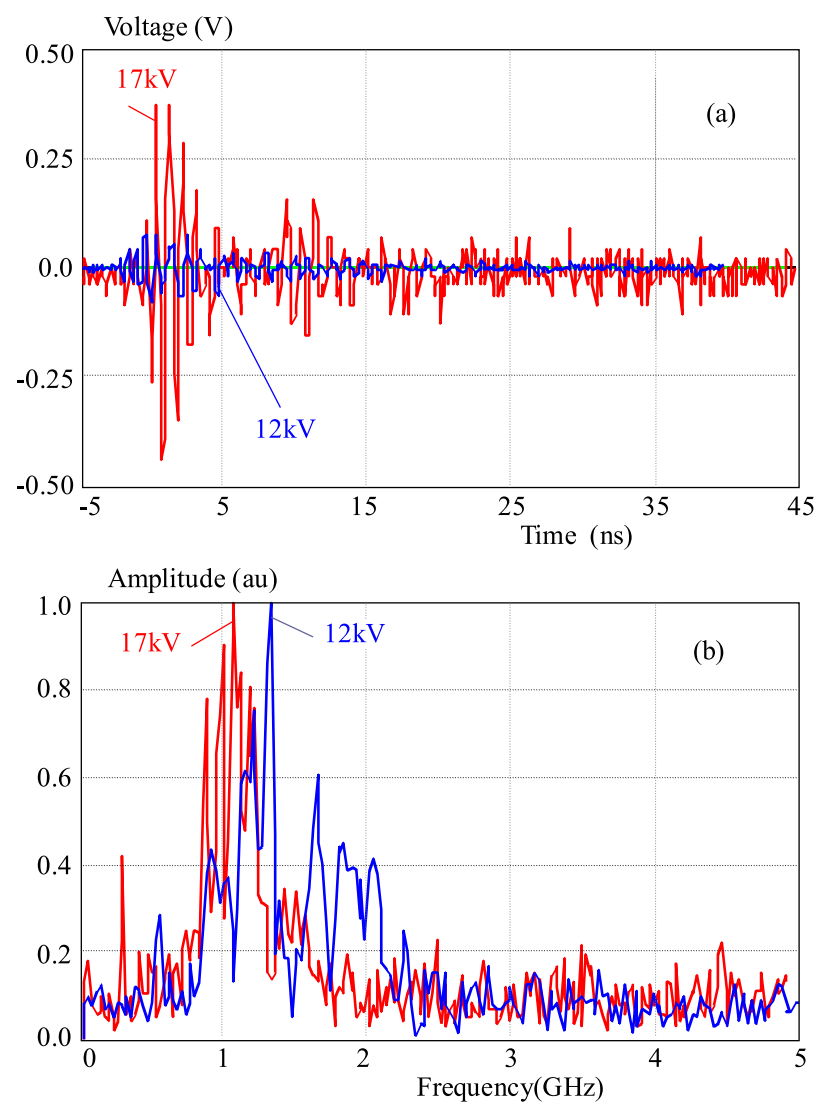

Fig. 6. Typical time domain UHF signal (a) and its corresponding FFT analysis (b) generated during tree growth at different voltages

\subsection{Analysis of UHF signal generated during tree growth}

This injected current due to partial discharges causing electrical tree are with rise time of few nano seconds. Figure 5 shows typical injected current signal generated due to partial discharges generated during tree propagation. It is well established that the rise time and fall time of the injected current pulse formed due to partial discharge signal in the $\mathrm{SF}_{6}$ insulation medium are of few nanoseconds radiating UHF signals [6]. Figure 6 (i) and 
UHF magnitude (V)

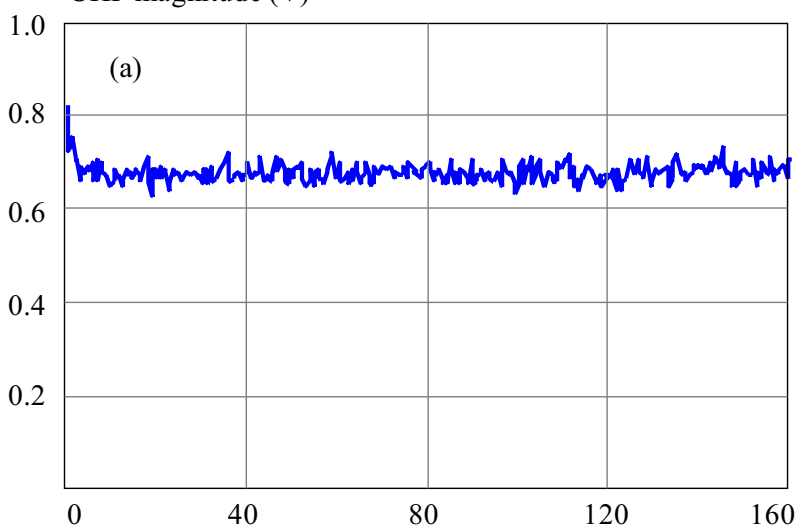

UHF magnitude (V)

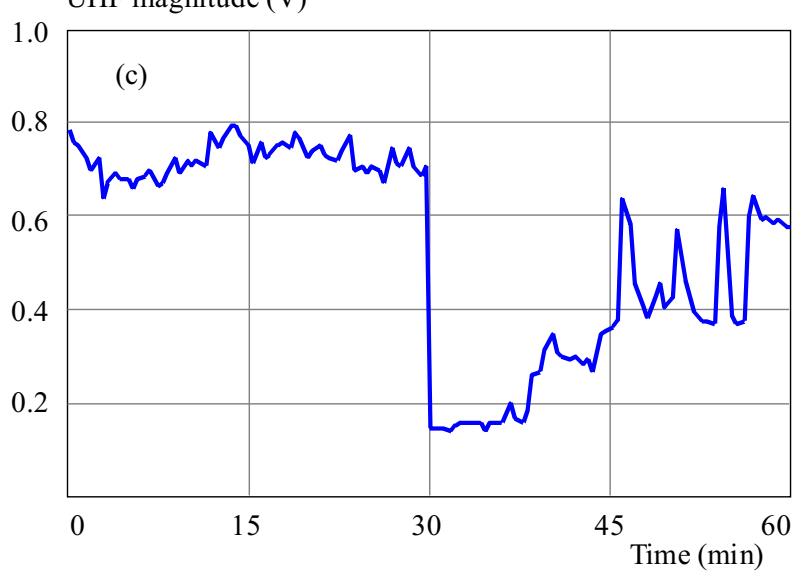



UHF magnitude (V)

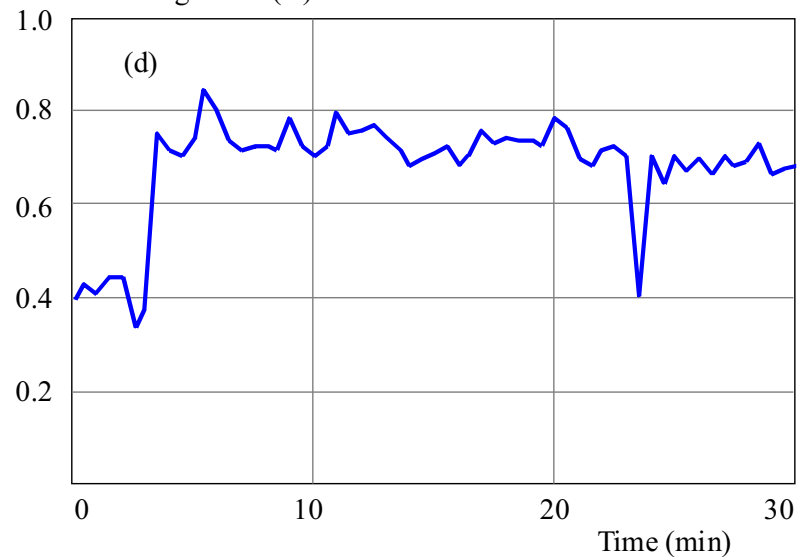

Fig. 7. Variation in UHF signal magnitude at the point of inception and while propagation of electrical tree. (a) Bush tree (b) Branch tree (c) Fibrillar tree (d) Intrinsic type tree

(ii) shows typical time domain UHF signal generated due to partial discharge formed owing to tree inception and propagation under $\mathrm{AC}$ voltages and the corresponding FFT analysis of the time domain signal respectively. It is observed that the characteristic frequency contents of the signal radiated due to partial discharges generated due to tree inception and propagation lies in the UHF signal range of $12 \mathrm{GHz}$. The characteristics of UHF signal is not much varied due to applied voltage and shape of tree formed. The intensity of the UHF signal measured varies depending on the type of tree structure formed. In general the magnitude of UHF is constant when a bush type tree forms and if the magnitude vary with time it forms tree like tree.

Figure 7 shows variation in UHF magnitude with respect to time during tree formation. Figure 7 a indicates that UHF magnitude is constant with respect to time, where a bush type of tree has formed. If the magnitude of signal alters much with time is the indication of tree like tree to form (Fig. 7b) and if bush type and tree like tree characteristics observed it is the indication of fibrillar type tree formation (Fig. 7c). A.G. Sellars carried out analysis of void discharge in epoxy resin insulation material and have concluded that streamer type and Townsend-type discharges occurs in the voids forming treeing leading to insulation failure [21]. They have identified that UHF signal gets generated only when streamer type discharge occurs and no UHF signal occurs when Townsend-type discharges occurs. The results of the present study also concludes the fact that when tree-liketree occurs streamer-type discharge predominates leading to high magnitude of UHF signal and a if consistent streamer type discharges occurs to form a bush type tree structure. When the magnitude of UHF signal formed increased suddenly and if it is constant, it is the indication of intrinsic-type tree formation (Fig. 7d). Thus it could be realized that formation of streamer type discharge and Townsend type discharges that occurs during tree inception and propagation alters the shape of the tree formed $[22,23]$. The measurement of UHF signal magnitude could provide only the global characteristics of shape of tree formed. It is essential to understand the tree dynamics and to classify the type of tree structure formed.

\subsection{Identification and Classification of different discharges using Ternary Diagram}

It is difficult to classify the type of tree pattern that forms from the UHF signal generated. In the present work, the partial power analysis to the UHF signal generated due to discharges was carried out, which will be the input data for generating the Ternary plot. Partial 

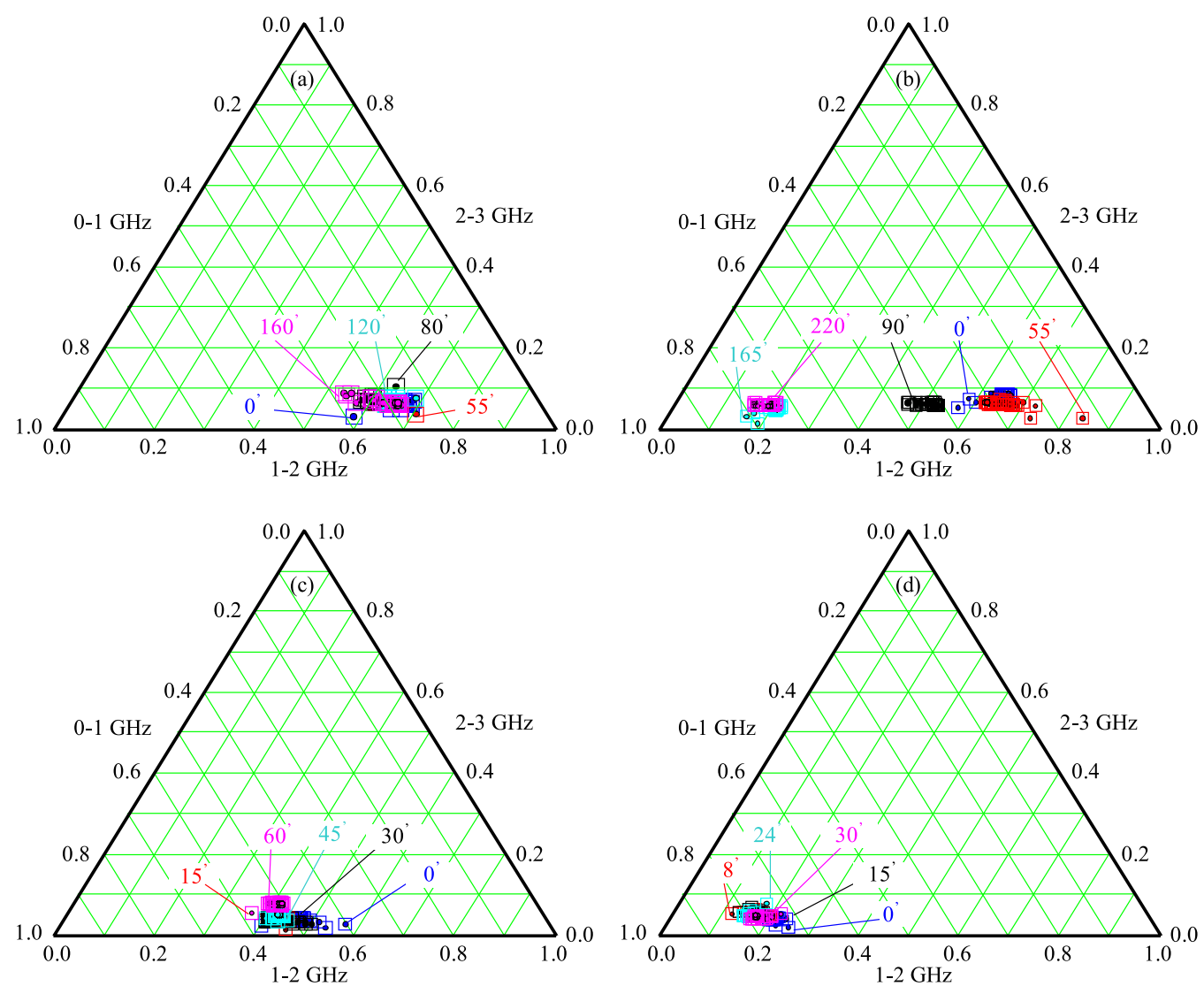

Fig. 8. Ternary diagram indicating the characteristics of the UHF signal generated due to different tree shapes (a) Bush tree (b) Branch tree (c) Fibrillar tree (d) Intrinsic type tree

Power is calculated by summing the power spectrum in a user specified range of frequencies, dividing it by the total power. The power spectrum was calculated up to $3 \mathrm{GHz}$ is split equally and the partial powers were calculated in three zones $(0-1 \mathrm{GHz}, 1-2 \mathrm{GHz}$ and $2-3 \mathrm{GHz})$. This normalisation technique is identical to the process used to generate the gas in oil ratio used to plot Duval's triangle [24]. P.C. Baker et al, carried out fundamental studies in GIS for identification of incipient discharges and have concluded that ternary plot analysis could allow one to identify the type of discharges in GIS [25]. Similar process is adopted to visualise and classify the type of tree pattern that occurs due to partial discharges, by construction of ternary plot. A clear separation of signal frequency contents occurs due to different tree patterns generated. Figure 8 Shows typical ternary diagram obtained for the signals generated during different tree patterns formed. The results of the study indicate that the Ternary diagram (shown in Fig. 8) can be used as condition monitoring tool for underground cables and could help one to classify the type of tree formed, for any remedial action, during operation. It is observed that, when bush type/tree like tree/fibrillar type trees/intrinsic type trees, it has unique location in the ternary plot allows one to classify and say the type of tree formed. Figure 6 a shows that energy content in UHF signal is high in the range $1.5-1.6 \mathrm{GHz}$ when bush type tree occurs and when a few branch causing intrinsic type tree the energy content of the UHF signal be high in the range 1.1 to $1.3 \mathrm{GHz}$. When a fibrillar tree occur the energy content of the UHF signal is high in the range $1.4-1.5 \mathrm{GHz}$. The results of the study indicate that the ternary plot allows one to identify the type of tree that has formed during a time period, indicating the efficiency of technique for identification and categorization of tree structure.

\section{CONCLUSIONS}

The major cause of failure of underground cable insulation during operation is due to electrical treeing. Various tree structures can form from a defect site Viz., Bush type tree, tree like tree, fibrillar type tree, intrinsic type, depending on the applied voltage. Weibull study indicates that higher the applied voltage enhances the rate of tree propagation thereby reducing the life of cable insulation. Measurement of injected current during tree propagation indicates that the rise time and fall time of the signal is of few nano seconds, thereby radiating UHG signals. By adopting the UHF technique, it is possible to identify the incipient discharges caused due to inception and propagation of electrical trees. It is realized that UHF signals generated during tree growth have signal bandwidth in the range of $0.5-2.0 \mathrm{GHz}$. The formation of streamer-type 
discharge and Townsend discharges during tree inception and propagation alters the shape of the tree formed. Analysis of UHF signals generated due to discharges formed during tree growth adopting Ternary plot can allow one to classify the shape of tree structure.

\section{Acknowledgements}

The authors wishes to thank Dr M. D. Judd, University of Strathclyde for his kind support in carrying out the present study. The Author (RS) wish to thank Department of Science and Technology, New Delhi for their funding to carry out the work on identification of incipient discharges in power system network adopting UHF technique.

\section{REFERENCES}

[1] EICHHORN, R. M.: IEEE Trans. On Electrical Insulation EI-12 No. 1 (1976), 2-18.

[2] Dissado, L. A.-FOTHERGiLl, J. C.: Electrical Degradation and Breakdown in Polymers, Peter Peregrinus ltd., London, 1992.

[3] DENSLEY, R. J.: IEEE Trans. On Electrical Insulation EI-14 No. 3 (1979), 148-158.

[4] MASAYUKI IEDA: IEEE Trans. On Electrical Insulation EI-15 No. 3 (1980), 206-224.

[5] KANEIWA, H.-SUZUOKI, Y.-MIZUTANI, T. : IEEE Trans. On Dielectrics and Electrical Insulation 8 No. 1, (2001), 72-77.

[6] JUDD, M. D.-FARISH, O.-HAMPTON, B. F. : The Excitation of UHF Signals by Partial Discharges in GIS, IEEE Transactions on Dielectrics and Electrical Insulation 3 No. 2 (1996), 213-228.

[7] LAURANT, C.-MAYOUX, C.: IEEE Trans. On Electrical Insulation EI-15 No. 1 (1980), 33-42.

[8] CAVAllini, A.-CONTI, M.-MONTANARI, G. C.-ARLOTTI, C.-CONTIN, A.: IEEE Transactions on Dielectrics and Electrical Insulation 11 No. 4, 2004.

[9] Guastavino, F.-CERUTTI, B.: IEEE Transactions on Dielectrics and Electrical Insulation 10 No. 1 (Feb 2003), 65-72.

[10] ANIL KUMAR, C. R.-DEEPA, S.-MISHRA, A. K.-SARATHI, R.: Polymer Testing 2 No. 3 (2003), 313-318.

[11] UENO, H.-NAGAMACHI, T.-NAKAMURA, M.-NAKAYAMA, H.-KAKIHANA, K.: Radiated Electro-Magnetic Waves Caused by Electrical Tree Development in Epoxy Resin, IEEJ Transactions on Fundamentals and Materials 129 No. 12 (2009), 915-921.

[12] JUDD, M. D.-FARISH, O.: A Pulsed GTEM System for UHF Sensor Calibration, IEEE trans. On Instrumentation and Measurement 47 No. 4 (1998), 875-880.

[13] JUDD, M. D.-LI YANG-HUNTER, IAN B. B. : IEEE Electrical Insulation Magazine 21 No. 2 (2005), 5-14.

[14] JUDD, M. D.-LI YANG-HUNTER, IAN B. B. : Partial Discharge Monitoring for Power Transformers using UHF Sensors Part-2: Field Experience, IEEE Electrical Insulation Magazine 21 No. 3 (2005), 5-13.

[15] MASON, J. H.: Brekadown of solid dielectrics in divergent fields, Proc. IEE 102 Part C (1955), 254-263.
16] AnshenG, X.-ZHENG, X.-SHEnGtAO, L.-CHEN, G.: The Conduction Characteristics of Electrical Trees in XLPE Cable Insulation, Journal of Applied Polymer Science 114 No. 5 (2009), 3325-3330.

[17] YOSHIMURA, N.-YANAGIWARA, M.-FAN, LI. G. : Diagnostics of Treeing Degradation by Image Processing, IEEE Transactions on Electrical Insulation 26 No. 2 (1991), 314-317.

[18] NELSON, W.: Applied Life Data Analysis, John Wiley and Sons, New York, 1982.

19] RAETZKE, S.-OHKI, Y.-IMAI, T.-TANAKA, T.-KINDERSBERGER, J.: Tree Initiation Characteristics of Epoxy Resin and Epoxy/Clay Nanocomoposite, IEEE Transactions on Dielectrics and Electrical Insulation 16 No. 5 (2009), 1473-1480.

20] XIE, A.-ShengtaO, L.-ZHENG, X.-CHEN, G.: The Characteristics of Electrical Trees in the Inner and Outer Layers of Different Voltage Rating XLPE Cable Insulation, Journal of Physics D: Applied Physics 42 No. 12 (2009).

[21] SELLARS, A. G.-FARISH, O.-HAMPTON, B. F.-PRITCHARD, L. S.: Using the UHF Technique to Investigate PD Produced by Defects in Solid Insulation, IEEE Trans. On Dielectrics Electrical Insulation 2 No. 3 (2005), 448-459.

[22] DANIKAS, M. G.: Small Partial Discharges and their Role in Insulation Deterioration, IEEE Trans. Diel. Elec. Insul. 4 No. 6 (1997), 863-867.

[23] DANIKAS, M. G.: On the Damage of Insulating Materials below Inception Voltage, J. Electr. Eng. 52 No. 11-12 (2001), 367-371.

[24] DUVAL: A Review of Faults Detectable by Gas in Oil Analysis in Transformers, IEEE Electrical Insulation Magazine 18 No. 3 (2002), 8-17.

25] BAKER, P. C.-BAKER, P. C.-JUDD, M. D.-McARTHUR, S. D. J.: A Frequency Based RF Partial Discharge Detector for Low Power Wireless Sensing, IEEE Trans. On Dielectrics and Electrical Insulation 17 No. 1 (2010), 133-140.

Received 25 June 2010

Ramanujam Sarathi is currently Full Professor and Head of High Voltage Laboratory, Department of Electrical Engineering, IIT Madras, Chennai, India. He obtained his Phd from Indian Institute of Science, Bangalore in 1994. His research areas includes condition monitoring of power apparatus and nano materials.

Arya Nandini completed her Master Tech from IISc, Bangalore in the year 2003. She is now working as Lecturer in the department of Electrical Engineering, Goverment College of Engineering, Trivandrum, Kerala, India. At present she is carrying out her doctoral studies in IIT Madras in the area of electrical treeing in underground cables.

Michael G. Danikas is Professor with the Department of Electrical and Computer Engineering, Democritus University of Thrace (DUTh). He was with Eindhoven University of Technology, The Netherlands, and with ABB, Baden-Daettwil, Switzerland, before he joined DUTh. His research interests include breakdown in transformer oil, polymeric insulation breakdown processes, vacuum breakdown, partial discharge activity at inception voltages, simulation of electrical trees in polymeric materials and nanocomposites and partial discharges in rotating machine insulation 